\title{
As Faculdades de Direito na história do Brasil*.
}

\author{
Miguel Reale \\ Catedrático de Filosofia do Direito na Facul- \\ dade de Direito da Universidade de São Paulo \\ - Presidente do Instituto Brasileiro de \\ Filosofia.
}

\begin{abstract}
SUMÁrio: Temporalidade abstrata e conereta - A fundação dos cursos jurídicos no Brasil, em 1827, e sua significação histórica - Papel da Jurisprudência nas primeiras décadas do século $X I X$ - Ciência e economia - As garan tias jurídicas das liberdades individuais - Características de nosso tempo no tocante à problemática das ciências e da economia - A tarefa que hoje incumbe às Faculdades de Direito - A palavra e o mito - $O$ culto autêntico da tradição.
\end{abstract}

\section{I}

As comemorações do dia 11 de agôsto, já por si tão significativas e eloqüentes, revestem-se de insólita importância esta manhã, quando os corpos docente e discente da Faculdade de Direito de São Paulo se integram nos trabalhos da II Conferência Nacional de Advogados que, durante alguns dias, se dedicou aos problemas fundamentais da vida jurídica do País, fixando uma série de conclusões do mais alto alcance para a causa da Justiça.

* Reconstituição da conferência proferida no dia 11 de agôsto de 1960, no salão nobre da Faculdade de Direito da Universidade de São Paulo, em comemoração do 123.o aniversário da instauração dos cursos jurídicos no Brasil, e em homenagem aos participantes à "II Conferência Nacional de Advogados", reunida sob as Arcadas de 5 a 11 daquele mês. 
Esta Casa, costuma-se dizer, é uma casa da tradição, o que quer dizer, uma casa da história. E, se a efeméride de hoje é histórica, mister é que dediquemos um pouco de nossa atenção ao significado das Faculdades de Direito na cultura brasileira.

O tempo, bem o sabeis, no que êle tem de quantitativo, isto é, enquanto mero fluxo ou seriação de momentos, pouco ou nada representa. O tempo é igual, trate-se de séculos, de anos, ou de segundos. O tempo em si mesmo é vasio, incolor, adiáforo, mas se enriquece com a substáncia de nossas atividades e pensamentos. O que importa, pois, é o tempo vivido. Como é o homem que empresta tonalidade e intensidade ao tempo que passa, a história de uma instituição não se qualifica pelo aspecto numérico dos meses ou das semanas, mas pela intensidade existencial das horas. Há entidades que apenas "fluem" no tempo, carentes de autêntico sentido existencial, enquanto outras há que "duram" ou "perduram", na plena luz de sua continuidade vetorial, pela fôrça de atualização do passado no momento presente conscientemente vivido.

Consoante ensinamento fecundo da Filosofia contemporânea, a história não é um conglomerado de fatos passados, algo de estático projetado atrás de nós. Muda-se a posição do observador no tempo, e eis que os eventos pretéritos adquirem tonalidade nova, expostos à incidência de imprevistos ângulos interpretativos. Por mais que nos anime o amor pelas verdades objetivas e impessoais, mister é reconhecer que, enquanto nos empenhamos no plano concreto da ação e nos situamos entre as coordenadas da vida prática, há uma história para o Vaticano e outra para o Kremlin. Há uma história para o homem de 1960, como haverá outra para o de 2.060, o que já induziu um pensador peninsular, Ugo SPIRITo, a admitir, muito embora isto soe a paradoxo, a pergunta sôbre "o futuro do passado". 
$\mathrm{Na}$ realidade, quanto mais vivemos, mais nos aprofundamos nos tempos idos: é no futuro que se esconde o valor essencial do passado, e é através dêle que se esbatem os contornos e as perspectivas do autenticamente válido, enquanto que se dissolvem e se olvidam falsas glórias e vaidades caducas. Talvez o único progresso possível em Filosofia resulte das crescentes perspectivas históricas. Cada século vê Platão a seu modo, e é possível que o estejamos vendo melhor do que os gregos.

Nada mais razoável, por conseguinte, do que o continuo reexame de nossa situação histórica, aproveitando-nos do ensêjo dêste Congresso para analisarmos mais uma vez o significado da fundação dos cursos juridicos no Brasil, afim de aquilatarmos o seu efetivo papel na história nacional.

Nem tudo são desigualdades no evolver das épocas históricas, visto como certas fases podem apresentar coincidências impressionantes, pontos de contato que traduzem íntimas razões de correspondência e de harmonia. Desejo dizer-vos que o período em que surgiram as Faculdades de Direito no Brasil e os tempos atuais oferecem algo de semelhante, algo de comum que precisa ser bem examinado.

Quê representam as primeiras décadas do século XIX no cenário total da história do Ocidente? A humanidade mal saira da experiência revolucionária francesa e das guerras napoleônicas, dando passos firmes no sentido de uma nova era, marcada pela dupla aspiração de usufruir de liberdades jurìdicamente tuteladas, bem como dos benefícios materiais que insuspeitadas aplicações tecnológicas the iam propiciando.

A chamada "civilização burguesa" atingia um de seus momentos decisivos, caracterizado pelo crescente entrelacamento entre as descobertas científicas e a sua imediata utilização no plano econômico. Era êsse um fato original e deveras surpreendente. 
Antes do século XIX, com efeito, o homem não revelara preocupação avassaladora pela praxis, ou seja, pela conversão imediata de conquistas puramente teóricas em "bens de vida". Ainda prevalecia o modêlo do sábio grego, destacado do processar-se imediato da existência, concentrando em si mesmo, quase que contemplando a verdade científica com a serena atitude dos analistas das figuras geométricas. Sabe-se que Arqurmedes se irritava quando lhe propunham aplicações pragmáticas dos seus grandes princípios. A verdade explendia em si e por si, independentemente de qualquer reflexo no mundo do fazer humano. Mas o século XIX veio impor novas formas de pensar e de atualizar o pensamento, suscitando uma correlação cada vez mais íntima e fecunda entre o homem de pensamento e o de ação, até ao ponto de tornar-se difícil distinguir-se um do outro, como se o pensamento já fôsse, consoante advertência de Mazzını, um esbôço de ação. O pensamento deixou de valer como forma pura, para valer sempre para algo, no fluxo intencional e incessante da vida.

Foi dêsse encontro estupendo entre logos e praxis que surgiu a economia do século XIX, cujas estruturas e processos condicionam a sociedade contemporânea: economia fundada na ciência e tirando da ciência o seu potencial revolucionário.

A essas conjunturas histórico-culturais se ajustaram os ordenamentos jurídicos da época, através dos quadros legislativos e jurisprudênciais, os quais, tornando possível a máxima liberdade de iniciativa, estimularam as fôrças da vontade criadora. Os códigos, ligados ao nome de Napoleão Bonaparte, marcam o rítmo da nova consciência jurídica individualista e liberal, talvez por demais confiante no poder harmonizador das vontades individuais, mas destinada, apesar dos conhecidos abusos ensejados, a criar as condições objetivas e práticas, sem as quais as liberdades não poderiam ter passado do estágio de mera formu- 
lação legal para o atual de mais denso conteúdo social e econômico.

Não se olvide, por conseguinte, que os cursos jurídicos surgiram no Brasil no dealbar do capitalismo industrial, quando se deram as decisivas transformações técnico-científicas, que transformaram a fisionomia da comunidade ocidental. E de então, com ef eito, o primeiro tear mecânico, que veio alterar as relações de produção, realizando o sonho de Aristóteles, que, de certa forma, previra as conseqüências da mecanização do trabalho, ao profetizar a desnecessidade de servos no dia em que os fusos passassem a girar sem serem acionados pelo tecelão, ou seja, quando o instrumental técnico fôsse posto à disposição dos propósitos transformadores do homem.

Foi, ainda, na mesma época, que ocorreram prodigiosas mudanças no sistema de comunicações e de transportes, com a primeira locomotiva encurtando as distâncias, os primeiros barcos a vapor cruzando o Atlântico. As descobertas sucediam-se nos mais variados e inéditos campos do conhecimento, constituindo-se poderosos processos de explicação e de domínio da natureza. Em poucas décadas, graças aos progressos tecnológicos, transfigurava-se a face do globo. Elevava-se no horizonte histórico o homo faber, o fabricante incansável de instrumentos, o demiurgo dominado pela febre das criações incessantes. Já o gênio de GoETHE, fazendo o diagnóstico da época que seus olhos penetrantes descortinavam, pusera em realce, nos versos imortais do Fausto, a alteração radical operada na visão do mundo: "A princípio era a ação". Não mais o primado do logos dos helenos, plasmando os sistemas filosóficos e as formas harmoniosas das artes; não mais o predomínio da voluntas romana, projetando-se nos atos e sistemas ordenatórios da paz e da guerra; não mais a originalidade do verbo hebraicocristão, banhado na luz da transcendência, mas a ação como senhorio da natureza, disciplina científica das fôr- 
ças elementares do cosmos, dinamismo dirigido à conquista técnica de bens úteis à vida.

Não houve, é claro, imediata e generalizada consciência do significado do novo mundo que surgia da sombra das ambições humanas. Pelo contrário, ao aparecerem as primeiras formas de mecanização do trabalho, o homem assustou-se, perplexo. Ergueram-se protestos e travaram-se lutas, surdas apreensões e gritos de revolta houve. Apavoraram-se, por exemplo, os barqueiros de Paris quando viram os primeiros barcos a vapor subindo o Sena, vislumbrando nas inovações técnicas uma ameaça ao trabalho livre. Não compreendiam que, quanto mais se potenciavam os instrumentos da produção mecânica, maiores se tornavam as possibilidades do trabalho livre, perdendo êste o seu aspecto material ou físico, para adquirir crescente intelectualização, mais forte sôpro de espiritualidade. Quantos gemidos e quanto suor e sangue não iria custar, todavia, o Moloch mecânico até ser domado o seu primeiro impulso revolucionário!

Pois bem, enquanto tão profunda metamorfose se verificava no plano das ciências e da economia, não se pode dizer que os juristas tenham permanecido alheios ao sentido dos novos tempos. Já fiz alusão aos novos Códigos que ajudaram a plasmar a civilização burguesa, mas seria grave êrro não recordar que data dessa época o lançamento das bases da moderna Ciência do Direito, a qual iria abrir-se, ainda antes de findo o século, ao salutar movimento ético de socialização do jus.

Se houvesse necessidade de apontar um acontecimento revelador de nova consciência jurídica, recordaria a celebre polêmica entre Thibaut e Savigny, o primeiro desejoso de harmonizar o direito positivo com os ensinamentos tradicionais do jusnaturalismo racionalista, fiel, pois, à grande linha de Thomasius e KanT, e, portanto, partidário da imediata codificação do direito germânico, enquanto que o segundo, integrado no ímpeto renovador do romantismo, julgava inoportuna a idéia de um código, pregando 
antes o valor do direito espontâneamente brotando do "espírito do povo", do costume convertido gradativamente em lei, como fruto da incessante e esclarecida adaptação do saber e da técnica dos juristas às mutáveis situações histórico-sociais.

Não importa aqui indagar se a razão estava com Savigny ou com Thibaut. Bastará lembrar apenas que a polêmica versava sôbre o problema da codificação, sôbre as suas vantagens ou oportunidade, mas convictos ambos de que algo de novo estava sendo plasmado na cultura do Ocidente. Na realidade, é essa atitude crítica perante os primeiros códigos do século XIX que adquire especial relêvo. Não se tratava, em verdade, de apreciar códigos elaborados no crepúsculo de uma civilização, à maneira de Justiniano, que salvara em boa hora da barbárie iminente preciosos fragmentos da Ciência romana, mas sim de uma obra concluída na França no instante decisivo do triunfo da burguesia individualista e liberal.

$\mathrm{Na}$ realidade, quem, a meu ver, soube situar melhor o problema foi Hegel, com os seus Lineamentos de Filosofia do Direito, publicados em 1821, seis anos antes da fundação desta Faculdade. $O$ filósofo idealista enquadrava a questão num panorama mais amplo e concreto, legitimando os códigos como expressões vivas e dinâmicas do Espírito Objetivo, ou seja, do mundo históricocultural, ou, por outras palavras, como formas de autoconsciência nacional. Superava, assim, os pontos de vista unilaterais do racionalismo abstrato de Thibaut e do historicismo empírico da SavignY, mostrando que há dois erros que se equivalem: abster-se de sistematizar as leis de um povo, ou sistematizá-las de maneira abstrata e formal.

Se lembrarmos, outrossim, que foi na meditação das páginas filosófico-jurídicas de Hegel que o jovem KarL MARX estabeleceu as primeiras linhas de sua concepção da sociedade e do Estado, teremos equacionados os dados liminares da problemática jurídica que ainda nos cabe resolver. 
Qual era, porém, a preocupação dominante dos jurisconsultos no princípio do século passado, quando cooperavam na feitura de Códigos e indagavam de seus méritos e conveniência? Era o desejo de preservar a liberdade e as peculiaridades de cada povo, sem prejuízo dos valores da segurança, da certeza, da ordem e da universalidade. De forma que, quando no Brasil se constituiram as Faculdades de Direito, o momento era também dos juristas, cuja missão era preservar as prodigiosas conquistas realizadas, mas, sobretudo garantir as realizações futuras.

O difícil, o grave no Direito não é apenas assegurar o que já se conquistou, mas é, sem prejuízo do conquistado, garantir a liberdade constitutiva do espírito em suas projeções para imprevistas arremetidas históricas. O Direito será sempre uma entidade bifronte: um olhar voltado para o passado, na defesa daquilo que se converteu em patrimônio positivo da história; outro olhar desvendando o futuro, para a tutela das possibilidades infindáveis da pessoa humana.

Se as Faculdades de Direito surgiram no instante em que a nacionalidade brasileira se aprestava para afirmar-se no cenário americano, compondo em unidade os valores da tradição lusa e as exigências do Novo Mundo, não se poderá contestar o acêrto da grande iniciativa.

Já foi dito alhures que teria sido preferível iniciar a nova nacionalidade no aprendizado das ciências positivas, provendo-a de um cabedal de conhecimentos práticos e tecnológicos, afim de orientá-la rumo a valores econômicos e utilitários.

Tal afirmação revela, todavia, total desconhecimento do que foi a obra educacional de D. JoÃo VI, marcada por fundo sentido pragmático. Com a transferência da Coroa para o Brasil, em virtude das invasões napoleônicas, o príncipe regente cuidou, de preferência, da criação de cursos de caráter técnico, fundando, em 1808 a Academia da Marinha; em 1810 a Real Academia Militar, desenvolvimento natural da Escola de Fortificação existente desde 
1699 e reformada no Vice-Reinado do Conde de Rezende; Cursos de Cirurgia, Anatomia e Medicina, no Rio de Janeiro e na Bahia, de 1809 a 1813; ensino de Economia na Bahia, em 1808; de Agricultura, em 1812; de Química, em 1817; de Desenho técnico, em 1818, para não falar na famosa Escola Real de Ciências, Artes e Ofícios, instituída em 1816.

Quê mais se poderia exigir, dadas as conjunturas da época? Como não reconhecer que o plano educacional de D. JoÃo VI correspondia aos ditames mais atuais do progresso cultural?

Se no País, porém, ainda não havia condições sociais e econômicas objetivas, de molde a permitir que os institutos técnicos, recém-constituídos, pudessem produzir todos os benefícios dêles esperados, e se, ao depois, a elite da juventude estudiosa acorreu de preferência às novas Faculdades de Direito, é sinal que estas correspondiam mais vivamente às contingências de nossa evolução cultural.

$\mathrm{Na}$ realidade, os Cursos Jurídicos representaram o coroamento necessário de nosso ensino superior, passando a atuar não apenas como centros de formação de advogados, mas como institutos em que vicejavam também as atividades filosóficas, políticas, jornalísticas, econômicas, literárias e sociológicas, conglobando sob o signo da Jurisprudência, como em certa fase da era renascentista, tôdas as "humanidades".

De mais a mais, que haveria de mais urgente do que a formação de uma consciência jurídica própria, do que preparar os pressupostos teóricos indispensáveis à estrutura legal do País? Nada mais natural, portanto, que, logo na segunda geração dos juristas pátrios, os olhos de um Teixeira de Freitas se abrissem para a Escola Histórica de SAvigny.

Não devem merecer atenção, por conseguinte, aquêles que reputam ter sido nociva à formação da nacionalidade a projeção das duas Faculdades de Direito, de São Paulo e do Recife, por terem, julgam êles, estigmatizado a cul- 
tura brasileira com o gênio irrequieto e versátil do bacharel.

Pois eu quero proclamar, nesta manhã destinada ̀̀ auto-crítica, que nós juristas não temos motivos para volver ao passado melancólico olhar de penitentes.

Prevalecem, ao contrário, no tempo decorrido, razões de justa vaidade. Ajudamos, com efeito, a plasmar a nacionalidade brasileira assegurando-lhe as condições de liberdade de iniciativa e de respeito à ordem jurídica tão indispensáveis às transformações operadas em todos os planos da obra civilizadora realizada pelo Império e pela República; contrabalançamos ou mitigamos as tendências militaristas e caudilhistas que ainda perduram em outros Paísés da América Latina; rasgamos novos horizontes à cultura nacional, pelo sentido de universalidade que lhe infundimos. Sôbre tais pontos torna-se desnecessário insistir, pois êste assunto foi objeto da tese que ofereci ̀̀ consideração do plenário da Conferência, focalizando a missão do advogado na vida brasileira.

Pois bem, se as Faculdades de Direito surgiram no Brasil numa época de iniciação histórica, quando se abriam os horizontes da Ciência jungida à Economia, devemos pensar que existe certa coincidência com os tempos que hoje estamos vivendo. Quê há de mais significativo, em nossa época, neste dealbar inquieto da que já foi chamada a "era interplanetária", do que a Ciência cada vez mais subordinada à Economia e à Política, até ao ponto de converter-se em "serviço" primordial do Estado?

Ciência e Economia, entrelaçadas, correm o risco de uma estatalização crescente. Como tive a oportunidade de acentuar na tese já referida, torna-se quase inconcebível o sábio insulado em seu laboratório, onde uma centelha de gênio fazia resplandecer a fecundidade de uma hipótese. 
A tarefa científica exige, hoje em dia, enquadramento e sistema, bem como a assistência permanente e contínua dos órgãos estatais, ou então de imensas emprêsas privadas que atuam, às vêzes, como verdadeiros Estados dentro do Estado.

Por outro lado, cresce assustadoramente o número dos que dependem das esferas administrativas, integrados no âmbito das funções públicas, ao mesmo tempo que o Estado alarga e multiplica a sua ingerência em todos os ramos da atividade humana, suscitando incessantes conflitos entre jus libertatis e jus civitatis.

Vão seria pensar na possibilidade de restabelecer-se o modêlo clássico do Estado liberal, circunscrito às tarefas "essenciais" da distribuição da justiça e da defesa da ordem interna e externa, pois o intervencionismo e a planificação são fenômenos inamovíveis do complexo cultural a que pertencemos.

O imprescindível é, porém, saber afrontar o problema da organização política e social com coragem e prudência, para a plena salvaguarda prioritária da liberdade, assim como dos valores que marcam a individualidade de cada povo.

Os grandes problemas de nossa época continuam sendo, pois, os da liberdade e da nacionalidade. Mas, se a tarefa foi de certa forma fácil no início do século XIX, quando se procurava assegurar a liberdade dos individuos e das Nações no plano político-constitucional, e se acreditava na harmonia das vontades entregues a si mesmas, nós estamos hoje vivendo em um mundo no qual ninguém pode depositar esperanças no equilíbrio automático dos egoismos. Como aceitar o otimismo, por exemplo, de um Bastiat, comparando a dinâmica econômica às maravilhosas evoluções dos corpos celestes num universo disciplinado matemàticamente $a b$ aeterno?

Sabemos todos que sem a fôrça disciplinadora do Direito não logrará êxito qualquer entendimento comum entre os homens no plano interno de cada Estado ou no 
das relações internacionais. Donde a missão pedagógica do Direito, a que se referia Montesquieu, pois as normas jurídicas não existem como fórmulas abstratas ou objeto de contemplação pura, mas são necessàriamente momentos de vida.

O fato de caracterizar-se a lei por sua aplicação, apresentando-se como a previsão de uma classe de comportamentos futuros, não deve nos levar ao equívoco de pensá-las como simples entidades lógicas: o seu conteúdo, o seu significado são complexos axiológicos e fáticos, correlacionados ou coimplicados segundo uma dialética que reflete tôda a ambivalência do ser humano, servo, ao mesmo tempo, da realidade e do ideal.

Não confundamos, portanto, o Direito com um conglomerado de preceitos técnicos, nem a Jurisprudência com a anatomia descritiva de estruturas formais erradicadas do concreto palpitar da existência humana.

Ai das Faculdades de Direito que se convertem em meras Escolas de advogados: reduzem-se a melancólicos objetores de falsos conhecedores da lei, porque escravos de fichas e formulários, perdido o sentido filosófico, o político e o sociológico, que emprestam dignidade ética e título cientifico à Jurisprudência.

As Faculdades de Direito não surgem, nem se justificam apenas para fins de formação profissional. Têm elas a finalidade de formar advogados, é certo, mas advogados que tenham sido, antes de mais nada, juristas, dotados da visão integral e concreta do Direito. Nada mais perigoso para a sociedade, sobretudo num momento como êste, do que o advogado submerso em preocupações de ordem estritamente profissional, esquecido de seus deveres de homem e de cidadão.

Há mais de três décadas que estudo Filosofia jurídica e, no entanto, envaideço-me de ser advogado profissional. Se me foi dado entender, com mais concretitude, certos aspectos do mundo jurídico, devo-o ao convívio diário com as lides forenses que me permitem pôr em cotêjo perma- 
nente as idéias do Direito e as suas vivências na relatividade da experiência histórica. Da mesma forma, mister é que o advogado não perca totalmente de vista os pressupostos ideológicos que condicionam a sua atividade profissional cotidiana.

O justo equilíbrio de uma Faculdade de Direito estará, por conseguinte, em saber elevar a mocidade ao plano mais alto, em que se debatem as idéias gerais e os princípios, sem olvido das exigências práticas com que se haverá de defrontar o futuro advogado.

Saber conciliar tais fatôres é a sabedoria que está sendo reclamada da prudência das Faculdades de Direito do País, cabendo, porém, maior soma de responsabilidades à Faculdade de Direito de São Paulo e à do Recife, por serem senhoras de maior dimensão histórica numa Nação pobre de raizes no tempo.

A tradição não pode pesar sôbre nossos ombros como capa de chumbo; deve, ao contrário, ser elemento de estímulo, de projeção para o futuro. A tradição pode ser uma palavra, e pode ser um mito.

É mister distinguir entre mito e palavra. A palavra é aderência ao ser. Adequação concreta ao real, amoldase a tôdas as peculiaridades das coisas significadas. O mito é a palavra que se desprendeu do ser, passando a ter significado autônomo, segundo valores próprios, imanentes: vale como entidade $a$ se, às vêzes em conflito com as camadas originárias do ser de que promana.

Quando se passa da palavra ao mito, aquela perde em racionalidade o que êste adquire de pura fôrça emocional. Pela palavra opera-se a comunicação intelectual entre os homens, possibilitando a luz da compreensão. Pelo mito, os homens se ordenam segundo algo que, tendo brotado dêles, se põe, no entanto, acima dêles, e os subjuga, quando não os esmaga. Para que prevaleça o mito bastá que as sombras da paixão se alarguem, interpondo-se entre o intelecto e a vida. 
Palavras há dotadas de maior ou menor carga emotiva, pois, como dimensões do homem, quando elas se ligam à problemática do destino humano (tal acontece com têrmos como liberdade, igualdade, democracia, socialização, nacionalismo, etc.) participam do que há em nós de dionisíaco e de apolíneo. Só as palavras mortas ou as neutras para os valores da vida se reduzem a meras formas. As que se integram em nosso viver coloram-se de tonalidade emocional. Não se pode pretender, pois, senão uma conjugação de fôrças em relativo equilíbrio. Se na palavra o poder dionisíaco pudesse se identificar integralmente com o puro conceito apolíneo, atingindo a unidade absoluta, estaríamos transcendendo a esfera do humano, intuindo o mistério do Verbo.

Mas, se em tôda palavra de alcance existencial se combinam o conceitual e o afetivo, êste dando calor à luz fria do intelecto, o ideal seria a polaridade harmônica dos dois fatôres, graças ao amor do universal concreto, ou, por outras palavras, do valor em uma totalidade de significados.

Ora, o valor da tradição, lançado no borborinho da comunidade acadêmica, tanto pode ter a fôrça vivificante de uma palavra, como o desregramento de um mito. Pode ser a expressão de um elo que nos prende orgulhosamente ao passado, abrindo perspectivas conscientes de déveres e de responsabilidades no presente e no futuro; e pode, ao contrário, ser o endeusamento emocional do passado para disfarce dos que melancòlicamente se omitem, ou então se apegam a processos rotineiros de cultura, incapazes de corresponder às exigências atuais da autêntica formação científica.

Há uma tradição radiosa que nos faz viver o passado, historicìsticamente, como atualidade presente; e há uma tradição obscura e triste, feita de renúncias irreparáveis, pesando como capa de chumbo sôbre os ombros de uma juventude que aguarda passivamente o futuro, como se êste fôsse uma dádiva e não uma conquista. 
Na curta história cultural das Américas, 133 anos, que tantos tem a nossa Faculdade, já representariam por si só um valor de tradição. Representam mais, todavia, se pensarmos na intensidade do "tempo vivido" por jovens como Alvares de Azevedo, Castro Alves e FagunDEs Varela, e por essa plêiade de homens ilustres que projetaram sôbre os quadrantes da pátria brasileira a luz votiva das Arcadas.

Graças aos que souberam viver o segrêdo dos segundos, multiplicou-se o nosso tempo existencial, inserindo-se a tradição da Academia na história brasileira, como uma de suas componentes inscindiveis. Por sermos os que mais podemos falar de tradição, mais devemos fazer por merecê-la.

Imensa é, em verdade, a nossa responsabilidade, para nấo comparecermos aos olhos dos contemporâneos como meras "viuvas da tradição". Se nos divorciarmos dos deveres que cada época atribui às novas gerações, como ineludivel tributo do tempo; se nos perdermos no gôzo fácil das glórias do passado; se, pior ainda, nos engalanarmos com falsos ouropéis, mascarando com "tradições aparentes" a vacuidade de uma existência sem rumo, nem sentido, correremos o risco de sermos as "viuvas alegres da tradição", o que talvez fôsse do agrado de certa gente que se julga guia e senhora da hora presente e futura.

Esta nossa Faculdade ostenta uma bela e imorredoura tradição que, ao ver de alguém, teria sido talvez menos de letras jurídicas do que de valores da Política e da Poesia, mas que também se espraia pelos planos da Diplomacia, do Jornalismo, da Economia, da Filosofia.

Durante algum tempo não se sabia ao certo se se entrava nesta Casa como poeta para sair-se jurista, ou se nela se ingressava com vocação jurídica para encontrar-se a Poesia. 
Se me fôsse dado formular um voto sốbre o nosso destino, desejaria que o Direito jamais se divorciasse da Poesia.

A poesia é o mito que se condensou novamente em palavras, que deixou o abstrato para se tornar plenitude e concreção. O risco do jurista é perder-se no emaranhado artificial das convenções e das fórmulas: tocado de um sôpro de Poesia, saberá unir às fórmulas dogmáticas a palpitação extuante da vida.

Cultivemos, em suma, a tradição, mas como quem se achega a um altar: não para subir sôbre êle e pavonear a própria vaidade, mas para o gesto humilde do crente, que sabe dar o melhor de si, na serena beleza da dedicação e da oferta.

É necessário, repito, manter a polaridade entre o mito e a palavra. Nunca a palavra na sua frieza racional, mas também não só o mito na sua irracionalidade transbordante. Devemos harmonizar, nós os juristas, a beleza apolínea das formas atualizadas com o dionisíaco esplendor das idéias em perene desabrochar, a tradição como conceito e como fôrça ideológica.

E se nessa tensão para o futuro, parecer-nos já acanhado e pequeno o mundo em que labutamos, tomados da paixão ardente de inéditas conquistas, não será demais recordar a lição do Sumo Pontífice Joño XXIII, ao advertir-nos que, se há outros mundos a conquistar, muitas, infinitas coisas ainda nos restam a fazer de amor e de bondade neste nosso mísero planeta.

Mas para que a luz do amor esclareça os homens e as coisas, há uma lâmpada votiva a ser mantida dia e noite acesa, que é a do Direito e da Justiça. A nossa medida, a medida do jurista, não está em nós, mas no próximo. Vivemos debruçados sôbre a sociedade, a descobrir carinhosamente as perspectivas e os limites da conduta alheia, e com isto cada vez mais avulta a nossa riqueza ética, visto como a justiça se torna tanto mais nossa quanto mais a distribuimos a quem a merece. De- 
vemos manter-nos fiéis à alta tarefa de distribuir justiça, mas justiça concreta, tal como é reclamada pelo mundo de hoje, a fim de que o nosso tempo seja cada vez mais tempo vivido, pois, já vos dizia de início, o tempo em si mesmo é incolor e adiáforo, havendo o instante rubro do delito assim como há o instante azul do perdão.

Com os olhos postos na história desta Faculdade. saibamos realizar tais obras de ciência e de virtude que o futuro possa aumentar ainda mais o esplendor do passado! 